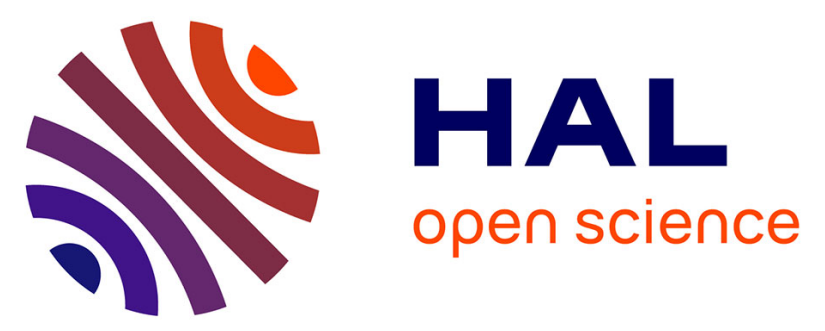

\title{
Benevolent and Corrective Humor, Life Satisfaction, and Broad Humor Dimensions: Extending the Nomological Network of the BenCor Across 25 Countries
}

\author{
Sonja Heintz, Willibald Ruch, Simge Aykan, Ingrid Brdar, Dorota \\ Brzozowska, Hugo Carretero-Dios, Hsueh-Chih Chen, Wladyslaw Chlopicki, \\ Incheol Choi, Alberto Dionigi, et al.
}

\section{To cite this version:}

Sonja Heintz, Willibald Ruch, Simge Aykan, Ingrid Brdar, Dorota Brzozowska, et al.. Benevolent and Corrective Humor, Life Satisfaction, and Broad Humor Dimensions: Extending the Nomological Network of the BenCor Across 25 Countries. Journal of Happiness Studies, 2020, 21 (7), pp.2473-2492. 10.1007/s10902-019-00185-9 . hal-02932110

\section{HAL Id: hal-02932110 \\ https://hal.univ-lorraine.fr/hal-02932110}

Submitted on 7 Sep 2020

HAL is a multi-disciplinary open access archive for the deposit and dissemination of scientific research documents, whether they are published or not. The documents may come from teaching and research institutions in France or abroad, or from public or private research centers.
L'archive ouverte pluridisciplinaire HAL, est destinée au dépôt et à la diffusion de documents scientifiques de niveau recherche, publiés ou non, émanant des établissements d'enseignement et de recherche français ou étrangers, des laboratoires publics ou privés. 


\title{
Benevolent and Corrective Humor, Life Satisfaction, and Broad Humor Dimensions: Extending the Nomological Network of the BenCor Across 25 Countries
}

\author{
Sonja Heintz, et al. [full author details at the end of the article]
}

(c) Springer Nature B.V. 2019

\begin{abstract}
Benevolent and corrective humor are two comic styles that have been related to virtue, morality, and character strengths. A previous study also supported the viability of measuring these two styles with the BenCor in 22 countries. The present study extends the previous one by including further countries (a total of 25 countries in 29 samples with $N=7813$ ), by testing the revised BenCor (BenCor-R), and by adding two criterion measures to assess life satisfaction and four broad humor dimensions (social fun/entertaining humor, mockery, humor ineptness, and cognitive/reflective humor). As expected, the BenCor-R showed mostly promising psychometric properties (internal consistency and factorial validity). Consistent with previous studies, benevolent humor correlated positively with life satisfaction in most countries, while corrective humor was uncorrelated with life satisfaction. These relationships were only slightly changed when controlling for social fun/entertaining humor and mockery, respectively. Benevolent humor was mostly positively associated with cognitive/reflective humor, followed by social fun/entertaining humor and mockery. Corrective humor was mostly positively associated with mockery, followed by cognitive/ reflective and social fun/entertaining humor, although these relationships differed between the countries. Overall, the present study supports the viability of benevolent and corrective humor, which has yet received insufficient attention in psychology, for cross-cultural investigations and applications of humor, well-being, and morality.
\end{abstract}

Keywords Humor $\cdot$ Life satisfaction $\cdot$ Cross-cultural comparisons $\cdot$ BenCor

\section{Introduction}

In psychology, humor has been recognized as a possible source of well-being for almost 100 years, starting with Sigmund Freud's essay on humor as a mature defense mechanism (1928). Humor has been broadly defined as encompassing all phenomena related to the

Electronic supplementary material The online version of this article (https://doi.org/10.1007/s 1090 2-019-00185-9) contains supplementary material, which is available to authorized users. 
funny or the comic (Martin and Ford 2018; Ruch et al. 2018a). Research has shown that some humor and comic styles ${ }^{1}$ might be more beneficial than others, but some styles might be potentially harmful (Martin and Ford 2018; Martin et al. 2003; Ruch et al. 2018b). While the relationship between humor and its different styles with well-being has been intensively studied, little is known about the cross-cultural consistency of these relationships. The present study thus combines humor with positive-psychology and cross-cultural perspectives to determine how two comic styles, benevolent and corrective, relate to life satisfaction in 25 countries. Furthermore, benevolent and corrective humor are related to four broader and more abstract humor dimensions (social fun/entertaining humor, mockery, humor ineptness, and cognitive/reflective humor) to see if they have similar connotations in each country. These results will provide information on the cross-cultural nomological network and criterion validity of the BenCor-R, the revised version of the 12 items assessing benevolent and corrective humor based on a previous cross-cultural study (Heintz et al. 2018).

\section{Benevolent and Corrective Humor}

Although benevolent and corrective humor have already been described in historical writings, these concepts have only recently been examined in psychology. Benevolent humor refers to an accepting and serene world view, in which wrongdoings and human weaknesses are considered part of everyday life and human nature (along the lines of "nobody's perfect"). This comic style is akin to the meaning that humor acquired during Renaissance humanism in the 19th century, and was deemed a cardinal virtue in England (Ruch and Heintz 2016). Descriptions of humor as a defense mechanism (Freud 1928), coping humor (Martin and Lefcourt 1983), self-enhancing humor (Martin et al. 2003), and humor as a character strength (Peterson and Seligman 2004) have been used to denote similar constructs (see also Heintz and Ruch 2019). In line with this conceptualization, benevolent humor was found to relate positively to character strengths (Ruch and Heintz 2016), subjective well-being (Ruch et al. 2018b), mindfulness (Hofmann et al. 2019), and happiness (Mendiburo-Seguel and Heintz 2019). Furthermore, it was investigated if these relationships were robust also when general sense of humor (Ruch and Heintz 2016) and Eysenck's (1991) three broad personality traits (psychoticism, extraversion, and neuroticism; Ruch et al. 2018b) were controlled for. The incremental validity of benevolent humor was supported for character strengths, positive and negative affect, and satisfaction with oneself, but not for life satisfaction. Thus, benevolent humor is a comic style relevant for positive traits and subjective well-being.

Corrective humor criticizes and mocks wrongdoings, misconduct, and moral transgressions of people and institutions, which is intended to improve them in the long term. Corrective humor has its root in satire, which originated as a term in the 2nd century (Milner Davis and Foyle 2017). This comic style is not conceptualized to be relevant for one's personal well-being, but rather should help societies thrive by encouraging people to uphold

\footnotetext{
1 In psychology, both terms, humor styles and comic styles, refer to individual differences in everyday funny/comical occurrences (i.e., detecting, appreciating, and producing funny stimuli, events, and utterances). The term humor style has been used with a focus on humorous conduct (Craik et al. 1996) and functions of humor (Martin et al. 2003). The term comic style originally denotes an aesthetic style or genre, and was recently transferred to psychology (Ruch et al. 2018a) to denote fine-grained individual differences in everyday funny/comical experiences (which includes benevolent and corrective humor/satire).
} 
consensual standards of moral conduct. In line with this conceptualization, research has shown that corrective humor is either uncorrelated or has small positive relationships with character strengths (Ruch and Heintz 2016), and it is not correlated with subjective wellbeing (Ruch et al. 2018b) or mindfulness (Hofmann et al. 2019). Finally, it appears to be only weakly related to happiness (Mendiburo-Seguel and Heintz 2019). Controlling for the three broad personality traits (and seven other comic styles) did not change the correlation of corrective humor with subjective well-being (Ruch et al. 2018b); however controlling for mockery (i.e., criticizing and making fun of others) resulted in positive relationships with the character strengths of bravery, fairness, and love of learning (Ruch and Heintz 2016). Thus, corrective humor is a comic style relevant for positive traits, but not for subjective well-being.

\section{Cross-Cultural Comparisons of the Relationships Between Humor and Well-Being}

Most humor research has focused on the relationships between different forms of humor (such as humor styles, comic styles, or the sense of humor) and subjective well-being (e.g., Ford et al. 2016; Kazarian and Martin 2006; Kuiper et al. 2004; Martin et al. 1993, 2003; Mendiburo-Seguel and Heintz 2019; Ruch et al. 2018b). These studies consistently found that subjective well-being positively relates to some forms of humor (e.g., self-enhancing humor style, benevolent humor, sense of humor, coping humor), negatively with some forms (e.g., self-defeating humor style, cynicism), or not at all with others (e.g., aggressive humor style, corrective humor).

To the best of our knowledge, no study has yet systematically compared the relationships of humor and subjective well-being across several nations (cf. Chen and Martin 2007). Although no country-level comparisons seem yet available, a meta-analysis Schneider et al. (2018) considered geographic region (North America, Europe, and Asia) as a moderator. They compared the relationships between mental health and the Humor Styles Questionnaire (Martin et al. 2003), which assess the self-enhancing humor style (similar to benevolent humor; Heintz and Ruch 2019). This humor style related more strongly to optimism (positively) and depression (negatively) in North America than in Asia, while the European samples showed intermediate relationships. By contrast, no differences across the three regions were found for the relationships of the self-enhancing humor style with self-esteem and life satisfaction, which were positive in all regions. These results suggest that benevolent humor might also be positively related to life satisfaction in all cultures, although comparing individual countries provides a more-fine grained level of analysis than geographic regions.

Overall, cross-cultural comparisons of the relevance of humor for well-being are lacking, which is a gap addressed by the present study. Previous research has shown that culture can influence subjective well-being (e.g., Diener et al. 2003; Diener and Suh 2003; Oishi and Diener 2009); for example, differences in self-evaluations (enhancement vs. criticism), goal orientations (approach vs. avoidance), and cultural values related to differences in subjective well-being across countries. Additionally, domain-specific satisfactions (such as satisfaction with oneself and with one's freedom) contributed to varying degrees to the global life satisfaction in different countries. Similarly, country differences have been found in humor-related traits, such as humor as a character strength (McGrath 2015) and gelotophobia, the fear of being laughed at (Proyer et al. 2009), as well as in humorous materials, 
where differences in content were found for funny advertisements (Alden et al. 1993). Furthermore, cultural specificities in the sense of humor and joking have been extensively discussed in sociological studies (Davies 2012, 2017); for example, joke targets and topics vary predictably across countries (e.g., American lawyer jokes, Scottish and Australian self-directed humor). Given these cross-cultural differences in both subjective well-being and humor, it is plausible to expect similar differences in their mutual relationship across different countries.

\section{The Present Study}

Thus far, the criterion validity of the BenCor has only been studied in German-speaking (Heintz 2019; Hofmann et al. 2019; Ruch 2012a; Ruch and Heintz 2016; Ruch et al. 2018a, b) and Spanish-speaking samples (Mendiburo-Seguel and Heintz 2019). Investigating the nomological network of the revised BenCor (BenCor-R) in different countries is thus a central next step to better understand how benevolent and corrective humor are interpreted in different cultural contexts.

The present study aims at exploring the relationships of benevolent and corrective humor with life satisfaction (Diener et al. 1985) and with four broad dimensions of humor (Ruch 2012a, b; Ruch and Heintz 2019) in 25 countries. Based on previous findings in Germany and Switzerland (Ruch and Heintz 2016; Ruch et al. 2018a) and most recently in Chile (Mendiburo-Seguel and Heintz 2019), we expect that benevolent humor will correlate positively with life satisfaction. Furthermore, it is expected that the incremental relationship of benevolent humor with life satisfaction beyond social fun/entertaining humor is still positive and significant. Although this is in contrast to the finding reported by Ruch et al. (2018b), we do not investigate the unique contribution of benevolent humor beyond broad personality traits and other specific humor styles (such as wit, nonsense, and irony), but instead test the extent benevolent humor retains its positive connotation once the more general dimension of social fun/entertaining humor is partialled out. In line with Schneider et al.'s (2018) lack of moderation effects for the relationship between the self-enhancing humor style and life satisfaction, we do not expect large cultural differences in these relationships with life satisfaction.

The relationship of corrective humor with life satisfaction is tested exploratively, as they are expected to be unrelated. Controlling for mockery should highlight the moral aim of this comic style rather than the criticism associated with it (see Ruch and Heintz 2016). We expect that the correlation between corrective humor and life satisfaction will thus become more positive. Cross-cultural differences for corrective humor might be more pronounced than for benevolent humor, as criticism against personal and societal wrongdoings is likely more influenced by cultural variations in "formal censorship (by editorial, legal or political decision)" and "internalized constraints (such as personal humor tastes and cultural conventions)" (Milner Davis 2016, p. 197).

Additionally, we investigate the relationships of the BenCor-R with broad humor dimensions to see whether benevolent and corrective humor are associated with similar dimensions across the countries or not. Recent research (Ruch 2012a, b; Ruch and Heintz 2019) has shown that at least four broad dimensions of humorous conduct should be distinguished (labeled social fun/entertaining humor, mockery, humor ineptness, and cognitive/ reflective humor). Ruch (2012a) already correlated the 12 BenCor items (which he labeled 
benevolent humor and moral mockery) with these four dimensions and found that benevolent humor mostly overlapped with social fun/entertaining humor and cognitive/reflective humor $(M d n r s=.35)$, but also with mockery $(M d n r s=.14)$ and negatively with humor ineptness $(M d n r=-.30)$. Corrective humor (which he labeled moral mockery) mostly overlapped with mockery ( $M d n r=.36)$, but also with social fun/entertaining humor and cognitive/reflective/benign humor $(M d n r s=.26)$, and was unrelated to humor ineptness (Mdn $r=.05)$. Thus, benevolent and corrective humor were uniquely embedded in the four broad humor dimensions.

In line with these findings, we expect that benevolent humor would correlate positively with social fun/entertaining humor and cognitive/reflective humor, negatively with humor ineptness, and positively (but small) with mockery. Corrective humor is predicted to correlate positively with social fun/entertaining humor, mockery, and cognitive/reflective humor. The relationship between corrective humor and humor ineptness is explored, as these two constructs are expected to be unrelated. As the cross-cultural relationships of corrective humor have not been studied before, we explore the similarities and differences between the individual samples. In general, the extent to which these relationships will be similar for the 25 countries and 29 samples under study will corroborate the cross-cultural nomological network of benevolent and corrective humor.

\section{Methods}

\subsection{Samples}

A total of 7813 adults from 25 countries participated in the study (see Table 1). Sample sizes in the 29 individual samples ranged from 109 (New Zealand) to 662 (Greece). To be included in the study, participants had to be at least 18 years old, had a good command of the language in which the study was conducted, and had to complete the BenCorR. Participants were excluded if they completed the BenCor too quickly (i.e., in less than 1 minute) or if they selected the same response for all items (i.e., response set). The gender distribution of the samples ranged from $23 \%$ females in Chile to $83 \%$ females in France ( $M=58 \%$ females). The average age ranged from 18.39 years in Canada to 41.20 years in New Zealand ( $M=28.64$ years). The sample consisted primarily of university students in 14 samples, primarily of workers/employees in 9 samples, and had a mixed composition in 6 samples. Data collection was conducted online in 23 samples, offline in 4 samples, and was mixed in 2 samples.

\subsection{Measures}

Revised BenCor (BenCor-R). The BenCor (Ruch 2012a) measures benevolent and corrective humor with 6 items each, using a seven-point Likert scale ranging from 1 (strongly disagree) to 7 (strongly agree). Sample items are "I am a realistic observer of human weaknesses, and my good-natured humor treats them benevolently" (benevolent humor) and "I have a critical attitude toward arrogant and unfair people and my mockery serves to establish equality and justice" (corrective humor). The internal consistencies and construct validity of the BenCor were supported in several studies conducted in different countries (e.g., Heintz et al. 2018; Ruch and Heintz 2016; Ruch et al. 2018a). As the previous crosscultural study identified three items that had cross-loadings, these items were rephrased in 
Table 1 Overview of the 29 BenCor samples in the 25 countries

\begin{tabular}{|c|c|c|c|c|c|c|}
\hline Samples & Language & $\mathrm{N}$ & $\% \mathrm{~F}$ & $M_{\text {age }}$ & Type & Mode \\
\hline Canada & English & 354 & 74 & 18.39 & Students & Online \\
\hline Czech Republic & Czech & 220 & 52 & 29.83 & $\mathrm{~S}$ and $\mathrm{W}$ & On-/offline \\
\hline Chile (mainly Santiago) & Spanish & 473 & 23 & 26.53 & $\mathrm{~S}$ and $\mathrm{W}$ & Online \\
\hline Croatia & Croatian & 213 & 47 & 21.66 & Students & Offline \\
\hline England & English & 123 & 72 & 29.03 & Students & Online \\
\hline Estonia & Estonian & 309 & 49 & 35.82 & Workers & Online \\
\hline France & French & 348 & 83 & 25.09 & Students & Online \\
\hline Germany & German & 260 & 56 & 23.16 & Students & Online \\
\hline Greece & Greek & 662 & 65 & 34.68 & Workers & Online \\
\hline Italy (mainly North) & Italian & 266 & 61 & 39.69 & Workers & Online \\
\hline Japan & Japanese & 201 & 50 & 20.23 & Students & Offline \\
\hline Latvia & Latvian & 401 & 76 & 39.91 & Workers & Online \\
\hline Malaysia (mainly Selangor and Kedah) & Malaysian & 225 & 48 & 22.98 & Students & Online \\
\hline Malaysia (mainly Terengganu) & Malaysian & 231 & 52 & 22.47 & Students & On-/offline \\
\hline Mexico (mainly Nuevo León) & Spanish & 143 & 67 & 24.22 & Workers & Online \\
\hline New Zealand & English & 109 & 74 & 41.20 & $\mathrm{~S}$ and $\mathrm{W}$ & Online \\
\hline Poland & Polish & 239 & 50 & 27.77 & Students & Online \\
\hline Romania & Romanian & 292 & 60 & $26.46^{\mathrm{a}}$ & Students & Offline \\
\hline Russia (mainly St. Petersburg) & Russian & 253 & 58 & 26.29 & $\mathrm{~S}$ and $\mathrm{W}$ & Online \\
\hline Russia (mainly Moscow) & Russian & 202 & 62 & 31.93 & Workers & Online \\
\hline Slovakia & Slovakian & 322 & 68 & 33.03 & $\mathrm{~S}$ and $\mathrm{W}$ & Online \\
\hline South Korea & Korean & 208 & 50 & 22.96 & Students & Online \\
\hline Spain & Spanish & 197 & 52 & 22.15 & Students & Offline \\
\hline Switzerland (mainly Zurich) & German & 436 & 42 & 23.66 & Students & Online \\
\hline Switzerland (mainly Vaud) & French & 135 & 56 & 39.69 & Workers & Online \\
\hline Taiwan & Taiwanese & 268 & 59 & 35.02 & Workers & Online \\
\hline Turkey (students) & Turkish & 314 & 73 & 21.96 & Students & Online \\
\hline Turkey (workers/employees) & Turkish & 225 & 51 & 33.40 & Workers & Online \\
\hline USA (mainly N.C.) & English & 184 & 56 & 31.41 & $\mathrm{~S}$ and $\mathrm{W}$ & Online \\
\hline
\end{tabular}

$\% F$ Percent of female participants, $S$ and $W$ mixed samples of students and workers

${ }^{\mathrm{a}}$ These results were averaged from six age groups rather than individual ages

the BenCor-R: Revised Item 3 (benevolent humor) "When my humor deals with human weaknesses, I refer to humans in general, including myself", revised Item 8 (corrective humor) "I make fun of my fellow humans' wrongdoings to urge them to change", and revised Item 12 (corrective humor) "If the circumstances are not as they actually should be, I ridicule these moral transgressions or societal wrongdoings to improve them in the long term".

Satisfaction with Life Scale (SWLS). The SWLS (Diener et al. 1985) is the standard measure for assessing life satisfaction, employing five items on a seven-point Likert scale ranging from 1 (strongly disagree) to 7 (strongly agree). A sample item is "I am satisfied with my life". Translated versions of the SWLS were available for all samples.

Four Dimensions of Humor Scale (4DHS). The 4DHS (Ruch 2012b) assesses markers of four broad dimensions of the sense of humor (Ruch 2012a; Ruch and Heintz 2019) with 
six items each. Sample items are "I have a reputation of being a funny entertainer" (social fun/entertaining), "I have an earthy, salty humor" (mockery), "I cannot laugh about my own weaknesses and failures" (humor ineptness), and "I like hearing and creating witty wordplays" (cognitive/reflective humor). The instrument employs a seven-point Likertscale from 1 (strongly disagree) to 7 (strongly agree). The 4DHS was not employed in eight samples due to time constraints (France, Japan, Latvia, Malaysia [Selangor \& Kedah], New Zealand, Russia [Moscow], Spain, and French-speaking Switzerland).

\subsection{Procedure}

If a translation was needed for conducting the study, the co-author received a standardized package for the translation of the BenCor-R, the 4DHS, and the data collection. They then followed a standardized translation/back-translation procedure (for details, see Heintz et al. 2018). The online samples were collected via different platforms (mostly SurveyMonkey). All samples are convenience samples, recruited via mailing lists, personal contacts, social media, university campuses, libraries, and lectures. In most samples, the BenCor-R was presented first, followed by the SWLS and the 4DHS. In some samples, this order was reversed or additional measures were employed that are not relevant for the present study.

Participants provided either online or written informed consent in accordance with the Declaration of Helsinki. Most samples were collected via a website provided by the University of Zurich; in accord with the ethical guidelines of the Ethics Committee of the Faculty of Arts, this study was exempt from ethics approval. Additional ethics approval was obtained in line with the local ethical guidelines with the following ethics committees: Ethics Review Committee on Human Research of Waseda University, Psychology Human Research Ethics Committee of the University of Waikato, Psychology Ethics Subject Panel of the University of Wolverhampton, Non-Medical Research Ethics Board of the University of Western Ontario, Institutional Review Board of the Western Carolina University, and the Institutional Review Board of the Seoul National University.

\subsection{Analyses}

The two-factor structure of the BenCor-R within each sample was investigated using confirmatory factor analyses (CFA) and the robust MLM estimator (with Satorra-Bentler corrections). The following fit indices were evaluated (cut-offs based on the recommendations by Schermelleh-Engel et al. 2003): $\chi^{2} / \mathrm{df}$ (good: $\leq 2$, acceptable: $\left.\leq 3\right)$, comparative fit index (CFI; good: $\geq .97$, acceptable: $\geq .95$ ), root mean square error of approximation (RMSEA; good: $\leq .05$, acceptable: $\leq .08$ ), and standardized root mean square residual (SRMR; good: $\leq .05$, acceptable: $\leq .10$ ). The lavaan package (Rosseel 2012) in $R$ (R Development Core Team2019) was used for the CFA analyses.

Measurement invariance across the two BenCor versions (original and revised) was tested in multi-group CFAs. The versions were compared across 18 samples in 16 countries that participated both in Heintz et al.'s (2018) study and in the present study (Chile, Croatia, England, Germany, Italy, Latvia, Malaysia [2 samples], Mexico, New Zealand, Poland, Russia [St. Petersburg], Slovakia, Spain, German-speaking Switzerland [students], Taiwan, Turkey [2 samples]). The levels of measurement invariance tested are configural invariance (same factor structure), metric invariance (same factor loadings), scalar invariance (same item intercepts), strict invariance (same residuals), and mean invariance (same latent means). The nested model was always compared to its parent model in terms of the 
difference in the $\chi^{2}$, CFI, and RMSEA values. As the $\chi^{2}$-difference test is sensitive to large sample sizes, changes of $\leq|.01|$ in the CFI and changes of $\leq|.015|$ in the RMSEA were used as additional cut-offs to indicate measurement invariance (Chen 2007; Cheung and Rensvold 1999). The semTools package (Jorgensen et al. 2018) in $R$ was used for the measurement invariance analyses.

Finally, correlations were computed between the two BenCor-R subscales and the SWLS and the 4DHS in each sample. Pearson correlations with bootstrapped $95 \%$ confidence intervals (CIs with 100 iterations) were computed using the Psych package (Revelle 2019) in $R$. To investigate the unique correlations of benevolent and corrective humor beyond social fun/entertaining and mockery, respectively, partial correlations were computed with $95 \%$ empirical CIs.

\section{Results}

\subsection{Preliminary Analyses of the BenCor-R}

To test if the item revisions and adaptations in the newly added countries (Canada, Czech Republic, Estonia, France, Greece, Japan, Romania, and South Korea) were successful, we first checked the descriptive statistics and psychometric properties of the BenCor-R (see Online Resources 1-3).

Online Resource 1 shows the descriptive statistics of the BenCor in the 29 samples. In line with the previous study (Heintz et al. 2018), the benevolent humor score was always numerically higher than the corrective humor score. The reliability (internal consistency) of the two scales was supported in all samples except for six samples in which the Cronbach alpha of benevolent humor was slightly lower than .60. The correlations among benevolent and corrective humor were positive and significant, except in one Malaysian sample (mainly Selangor \& Kedah; $r=.13$ ) and in New Zealand $(r=.06)$. Correlations were lower in the Czech Republic, England, Latvia, Mexico, Russia (St. Petersburg), and Taiwan $(r s=.13-.30)$ than in most other samples. Correlations were higher in Greece $(.52)$ and Romania (.60) than in most other samples.

Next, the two-factor structure in each sample was investigated using CFAs (see Online Resource 2). Most fit indices suggested an acceptable fit of the two-factor model in 24 samples, with the exception of Chile (mainly Santiago), Greece, Mexico (mainly Nuevo León), Russia (St. Petersburg), and Turkey (workers/employees sample).

Finally, the original and revised BenCor versions were compared across 18 samples. As can be seen in Online Resource 3, all levels of measurement invariance were supported based on the RMSEA difference (always $<1.015 \mathrm{l}$ ), while the CFI difference was once larger than I.01I (scalar invariance). For individual items, the intercepts of Items 3 and 8 (which were revised, along with Item 12) had the highest contributions to the lower model misfit (i.e., these items differed the most across the 18 samples). Overall, mean invariance was supported across both BenCor versions (original and revised), indicating that the mean scores and variances in benevolent and corrective humor were comparable. Taken together, these analyses suggest that the BenCor- $\mathrm{R}$ is comparable to the original BenCor, its psychometric properties were sufficient in most samples, and that benevolent and corrective humor represent two different, yet interrelated comic styles. Thus, the analyses of criterion correlations could be conducted. 
Table 2 Zero-order and partial correlations (controlling for social fun/entertaining humor) of benevolent humor with life satisfaction in each sample (29 samples in total)

\begin{tabular}{lllll}
\hline Samples & $r$ & $95 \% \mathrm{CI}$ & $r_{p}$ & $95 \% \mathrm{CI}$ \\
\hline Canada & .08 & {$[-.03, .20]$} & .05 & {$[-.05, .15]$} \\
Czech Republic & $\mathbf{. 2 5}$ & {$[.09, .40]$} & $\mathbf{. 2 2}$ & {$[.09, .34]$} \\
Chile (mainly Santiago) & $\mathbf{. 1 1}$ & {$[.01, .21]$} & .04 & {$[-.05, .13]$} \\
Croatia & $\mathbf{. 3 1}$ & {$[.14, .47]$} & $\mathbf{. 2 7}$ & {$[.14, .39]$} \\
England & .12 & {$[-.06, .29]$} & .05 & {$[-.09, .26]$} \\
Estonia & $\mathbf{. 2 7}$ & {$[.15, .37]$} & $\mathbf{. 1 9}$ & {$[.08, .30]$} \\
France & $\mathbf{. 1 5}$ & {$[.06, .26]$} & - & - \\
Germany & $\mathbf{. 1 9}$ & {$[.04, .33]$} & $\mathbf{. 1 6}$ & {$[.03, .29]$} \\
Greece & $\mathbf{. 1 1}$ & {$[.02, .21]$} & $\mathbf{. 0 9}$ & {$[.02, .17]$} \\
Italy (mainly North) & $\mathbf{. 2 5}$ & {$[.13, .36]$} & $\mathbf{. 1 9}$ & {$[.07, .31]$} \\
Japan & $\mathbf{. 2 3}$ & {$[.07, .35]$} & - & - \\
Latvia & $\mathbf{. 2 9}$ & {$[.20, .38]$} & - & - \\
Malaysia (mainly Selangor and Kedah) & $\mathbf{. 3 2}$ & {$[.20, .43]$} & - & - \\
Malaysia (mainly Terengganu) & $\mathbf{. 2 0}$ & {$[.06, .34]$} & .10 & {$[-.03, .23]$} \\
Mexico (mainly Nuevo León) & $\mathbf{. 3 1}$ & {$[.11, .50]$} & $\mathbf{. 2 5}$ & {$[.09, .40]$} \\
New Zealand & $\mathbf{. 2 4}$ & {$[.04, .42]$} & - & - \\
Poland & $\mathbf{. 2 2}$ & {$[.10, .34]$} & $\mathbf{. 1 8}$ & {$[.05, .30]$} \\
Romania & $\mathbf{. 1 2}$ & {$[.01, .24]$} & .08 & {$[-.04, .19]$} \\
Russia (mainly St. Petersburg) & $\mathbf{. 1 7}$ & {$[.05, .30]$} & $\mathbf{. 1 6}$ & {$[.04, .28]$} \\
Russia (mainly Moscow) & .15 & {$[-.01, .29]$} & - & - \\
Slovakia & $\mathbf{. 2 4}$ & {$[.13, .37]$} & $\mathbf{. 2 0}$ & {$[.10, .31]$} \\
South Korea & .10 & {$[-.02, .23]$} & .05 & {$[-.08, .19]$} \\
Spain & $\mathbf{. 1 5}$ & {$[.01, .31]$} & - & - \\
Switzerland (mainly Zurich) & .11 & {$[-.05, .24]$} & -.01 & {$[-.14, .12]$} \\
Switzerland (mainly Vaud) & .10 & {$[-.07, .29]$} & - & - \\
Taiwan & $\mathbf{. 3 1}$ & {$[.19, .42]$} & $\mathbf{. 2 6}$ & {$[.14, .37]$} \\
Turkey (students) & .08 & {$[-.07, .22]$} & .04 & {$[-.07, .16]$} \\
Turkey (workers/employees) & .08 & {$[-.07, .21]$} & .09 & {$[-.04, .23]$} \\
USA (mainly N.C.) & .15 & {$[.00, .30]$} & .08 & {$[-.07, .22]$} \\
Median correlation across all samples & .17 & & .10 & \\
\hline S5\% & & & - \\
\hline
\end{tabular}

95\% CI = bootstrapped 95\% confidence interval of the correlations $(r)$ and empirical $95 \% \mathrm{CI}$ of the partial correlations $\left(r_{p}\right)$

Significant correlations highlighted in bold

\subsection{Relationships with Life Satisfaction}

The correlations of the BenCor-R with life satisfaction were investigated next (see Tables 2 and 3). The SWLS worked well in each sample (see Online Resource 4), which is in line with previous cross-cultural findings on the scale (e.g., Kuppens et al. 2008). As expected, benevolent humor showed significant positive relationships with life satisfaction in 20 of the 29 samples; the remaining correlations were positive, yet not significant. When controlling for social fun/entertaining humor (i.e., the social aspect of humor), benevolent humor 
Table 3 Zero-order and partial correlations (controlling for mockery) of corrective humor with life satisfaction in each sample (29 samples in total)

\begin{tabular}{|c|c|c|c|c|}
\hline Samples & $r$ & $95 \% \mathrm{CI}$ & $r_{p}$ & $95 \% \mathrm{CI}$ \\
\hline Canada & -.12 & {$[-.23, .01]$} & -.08 & {$[-.18, .03]$} \\
\hline Czech Republic & .03 & {$[-.09, .17]$} & .06 & {$[-.07, .19]$} \\
\hline Chile (mainly Santiago) & .00 & {$[-.11, .12]$} & .02 & {$[-.06, .11]$} \\
\hline Croatia & .08 & {$[-.05, .22]$} & .12 & {$[-.02, .25]$} \\
\hline England & -.05 & {$[-.21, .11]$} & .02 & {$[-.15, .20]$} \\
\hline Estonia & .01 & {$[-.12, .12]$} & .02 & {$[-.09, .13]$} \\
\hline France & -.03 & {$[-.13, .07]$} & - & - \\
\hline Germany & .00 & {$[-.13, .11]$} & .07 & {$[-.06, .20]$} \\
\hline Greece & -.05 & {$[-.13, .03]$} & -.02 & {$[-.10, .06]$} \\
\hline Italy (mainly North) & .01 & {$[-.10, .11]$} & .01 & {$[-.11, .13]$} \\
\hline Japan & .02 & {$[-.13, .15]$} & - & - \\
\hline Latvia & -.04 & {$[-.14, .05]$} & - & - \\
\hline Malaysia (mainly Selangor and Kedah) & -.03 & {$[-.18, .12]$} & - & - \\
\hline Malaysia (mainly Terengganu) & .11 & {$[-.01, .25]$} & .03 & {$[-.10, .16]$} \\
\hline Mexico (mainly Nuevo León) & -.08 & {$[-.25, .11]$} & .08 & {$[-.09, .24]$} \\
\hline New Zealand & -.25 & {$[-.43,-.09]$} & - & - \\
\hline Poland & -.02 & {$[-.15, .13]$} & -.02 & {$[-.15, .10]$} \\
\hline Romania & .07 & {$[-.06, .20]$} & .15 & {$[.03, .26]$} \\
\hline Russia (mainly St. Petersburg) & -.08 & {$[-.20, .06]$} & -.02 & {$[-.15, .10]$} \\
\hline Russia (mainly Moscow) & -.01 & {$[-.15, .13]$} & - & - \\
\hline Slovakia & -.04 & {$[-.15, .07]$} & .00 & {$[-.11, .11]$} \\
\hline South Korea & -.13 & {$[-.27, .04]$} & -.09 & {$[-.22, .05]$} \\
\hline Spain & -.09 & {$[-.24, .05]$} & - & - \\
\hline Switzerland (mainly Zurich) & -.02 & {$[-.15, .10]$} & .03 & {$[-.10, .16]$} \\
\hline Switzerland (mainly Vaud) & -.09 & {$[-.26, .10]$} & - & - \\
\hline Taiwan & .00 & {$[-.12, .13]$} & .05 & {$[-.07, .17]$} \\
\hline Turkey (students) & -.23 & {$[-.33,-.12]$} & -.12 & {$[-.23, .00]$} \\
\hline Turkey (workers/employees) & -.17 & {$[-.30,-.06]$} & -.05 & {$[-.19,08]$} \\
\hline USA (mainly N.C.) & .09 & {$[-.08, .21]$} & .11 & {$[-.03, .25]$} \\
\hline Median correlation across all samples & -.03 & & .02 & \\
\hline
\end{tabular}

95\% CI = bootstrapped $95 \%$ confidence interval of the correlations $(r)$ and empirical $95 \% \mathrm{CI}$ of the partial correlations $\left(r_{p}\right)$

Significant correlations highlighted in bold

still showed significant positive correlations with life satisfaction in 11 of 20 samples. Overall, the median correlation of benevolent humor with life satisfaction was .17 and the partial correlation was .10, which correspond to small effects. Thus, benevolent humor was positively related to life satisfaction in 20 samples, and this relationship remained stable when a general humor dimension (social fun/entertaining) was accounted for in half of the samples.

For corrective humor, all correlations with life satisfaction were non-significant, except for the New Zealand $(r=-.25)$ and both Turkish samples $(r s=-.23$ and -.17$)$, which 
were significant and negative (see Table 3). All relationships were non-significant once mockery was controlled for, with the exception of Romania $\left(r_{p}=.15\right)$. This shows that corrective humor and also the moral aspect of this comic style were in general unrelated to life satisfaction across the 29 samples (median correlations -.03 to .02 , respectively).

\subsection{Relationships with Broad Humor Dimensions}

The 4DHS was employed for the first time in a cross-cultural study, with 21 samples completing the measure. As shown in Online Resource 5, the reliabilities of the social fun/ entertaining and mockery scales were sufficient in all samples (>.60). The cognitive/reflective humor scale showed sufficient reliabilities in 17 samples and was slightly below 60 in Canada, the Czech Republic, Poland, and Romania. The humor ineptness scale did not meet an acceptable standard of internal consistency, ranging from .37 to .56 (except for the U.S. sample with .75). Thus, the observed correlations with humor ineptness likely underestimate the true relationship with the BenCor-R. Online Resource 6 also shows the correlations of the four humor dimensions with life satisfaction. Social fun/entertaining humor correlated positively with life satisfaction in most samples, while humor ineptness correlated negatively in most samples. Mockery tended to correlate negatively and cognitive/ reflective humor tended to correlate positively with life satisfaction, although these correlations were non-significant in most samples.

The correlations of benevolent humor with social fun/entertaining and cognitive/ reflective humor were positive and significant in all samples (see Table 4). The correlation of benevolent humor with social fun/entertaining was especially high in the Taiwanese sample, and its correlation with cognitive/reflective humor was especially high in Romania, Taiwan, and the USA. Furthermore, the correlations of benevolent humor were always numerically higher with cognitive/reflective humor than with social fun/entertaining, except for the Czech Republic and Turkey (workers/employees). The correlations of benevolent humor with mockery were lower, but always positive and also significant in 18 samples, except for Italy, Russia (St. Petersburg), and Taiwan. The correlations of benevolent humor with humor ineptness were mostly non-significant, with negative correlations in four samples (Estonia, Germany, Greece, and Russia [St. Petersburg]) and a positive correlation in the Malaysian (Terengganu) sample. Thus, the correlations of benevolent humor with social fun/entertaining humor and with cognitive/reflective humor were as expected, while positive relationships were found with mockery and non-significant correlations with humor ineptness.

Finally, the correlations of corrective humor with the broad humor dimensions were investigated (see Table 5). The correlations of corrective humor with social fun/entertaining, mockery, and cognitive/reflective humor were positive and significant in all samples. The correlations of corrective humor were always numerically highest with mockery, except in the Chilean (higher with cognitive/reflective humor), German (higher with cognitive/reflective humor) and Romanian samples (higher correlations with social fun/entertaining and cognitive/reflective humor). The correlations of corrective humor with humor ineptness were positive and significant in 15 of the 21 samples. The relationship of corrective humor with humor ineptness was always numerically lower than the correlations with the other three humor dimensions, though it was higher in Mexico (Nuevo León; as high as the correlation with social fun/entertaining) and Taiwan (higher than the correlation with cognitive/reflective humor). Thus, the correlations of corrective humor with social fun/entertaining humor, 
Table 4 Criterion correlations of benevolent humor with the Four Dimensions of Humor Scale (4DHS) in each sample (21 samples in total)

\begin{tabular}{|c|c|c|c|c|c|c|c|c|}
\hline \multirow[t]{2}{*}{ Samples } & \multicolumn{2}{|c|}{$\begin{array}{l}\text { Social fun/ } \\
\text { entertaining }\end{array}$} & \multicolumn{2}{|c|}{ Mockery } & \multicolumn{2}{|c|}{ Humor ineptness } & \multicolumn{2}{|c|}{$\begin{array}{l}\text { Cognitive/ } \\
\text { reflective } \\
\text { humor }\end{array}$} \\
\hline & $r$ & $95 \% \mathrm{CI}$ & $r$ & $95 \% \mathrm{CI}$ & $r$ & $95 \% \mathrm{CI}$ & $r$ & $95 \% \mathrm{CI}$ \\
\hline Canada & .40 & {$[.28, .51]$} & .35 & {$[.25, .45]$} & .08 & {$[-.02, .18]$} & .57 & {$[.48, .65]$} \\
\hline Czech Republic & .35 & {$[.21, .48]$} & .14 & {$[.02, .27]$} & -.06 & {$[-.23, .09]$} & .35 & {$[.19, .49]$} \\
\hline Chile (mainly Santiago) & .33 & {$[.24, .43]$} & .27 & {$[.17, .37]$} & -.06 & {$[-.18, .06]$} & .43 & {$[.34, .53]$} \\
\hline Croatia & .45 & {$[.33, .55]$} & .30 & {$[.15, .44]$} & .10 & {$[-.03, .24]$} & .54 & {$[.42, .65]$} \\
\hline England & .26 & {$[.04, .47]$} & .23 & {$[.02, .44]$} & -.05 & {$[-.24, .16]$} & .44 & {$[.30, .58]$} \\
\hline Estonia & .42 & {$[.30, .52]$} & .20 & {$[.08, .29]$} & -.13 & {$[-.23,-.02]$} & .51 & {$[.41, .59]$} \\
\hline Germany & .28 & {$[.14, .41]$} & .19 & {$[.05, .33]$} & -.19 & {$[-.31,-.03]$} & .36 & {$[.24, .47]$} \\
\hline Greece & .47 & {$[.40, .54]$} & .28 & {$[.20, .35]$} & -.11 & {$[-.19,-.03]$} & .52 & {$[.45, .58]$} \\
\hline Italy (mainly North) & .41 & {$[.29, .51]$} & .11 & {$[-.03, .23]$} & -.05 & {$[-.18, .10]$} & .43 & {$[.32, .53]$} \\
\hline Malaysia (mainly Terengganu) & .40 & {$[.27, .51]$} & .35 & {$[.25, .44]$} & .28 & {$[.16, .39]$} & .51 & {$[.40, .60]$} \\
\hline Mexico (mainly Nuevo León) & .41 & {$[.27, .53]$} & .19 & {$[.01, .35]$} & .01 & {$[-.17, .20]$} & .49 & {$[.32, .61]$} \\
\hline Poland & .32 & {$[.19, .43]$} & .17 & {$[.06, .28]$} & -.09 & {$[-.19, .02]$} & .38 & {$[.26, .47]$} \\
\hline Romania & .39 & {$[.28, .49]$} & .16 & {$[.05, .27]$} & .05 & {$[-.07, .16]$} & .60 & {$[.51, .67]$} \\
\hline Russia (mainly St. Petersburg) & .29 & {$[.18, .41]$} & .11 & {$[-.02, .24]$} & -.14 & {$[-.26,-.02]$} & .39 & {$[.29, .49]$} \\
\hline Slovakia & .41 & {$[.31, .50]$} & .26 & {$[.12, .36]$} & -.05 & {$[-.18, .08]$} & .53 & {$[.44, .62]$} \\
\hline South Korea & .41 & {$[.28, .52]$} & .17 & {$[.02, .32]$} & .07 & {$[-.10, .23]$} & .50 & {$[.37, .61]$} \\
\hline Switzerland (mainly Zurich) & .46 & {$[.32, .58]$} & .48 & {$[.35, .59]$} & .05 & {$[-.10, .19]$} & .58 & {$[.46, .68]$} \\
\hline Taiwan & .57 & {$[.47, .65]$} & .07 & {$[-.04, .16]$} & -.08 & {$[-.20, .03]$} & .61 & {$[.53, .69]$} \\
\hline Turkey (students) & .40 & {$[.29, .50]$} & .32 & {$[.23, .41]$} & .00 & {$[-.12, .11]$} & .49 & {$[.39, .57]$} \\
\hline Turkey (workers/emp & .48 & {$[.37, .58]$} & .27 & {$[.17, .36]$} & .06 & {$[-.08, .17]$} & .47 & {$[.33, .57]$} \\
\hline USA (mainly N.C.) & .44 & {$[.32, .57]$} & .33 & {$[.18, .48]$} & .06 & {$[-.09, .21]$} & .63 & {$[.51, .74]$} \\
\hline Median across all samples & .41 & & .23 & & -.05 & & .50 & \\
\hline
\end{tabular}

95\% CI = bootstrapped $95 \%$ confidence interval of the correlations $(r)$

Significant correlations highlighted in bold

mockery, and cognitive/reflective humor were as expected, though unexpected positive relations emerged to humor ineptness.

\section{Discussion}

The present study examined the relationships of benevolent and corrective humor with life satisfaction and four broad dimensions of humor in 25 countries. As expected, benevolent humor correlated positively with life satisfaction in most countries, and in half of the samples this relationship was also found when controlling for social fun/entertaining humor. This is in line with previous research (Mendiburo-Seguel and Heintz 2019; Ruch and Heintz 2016; Ruch et al. 2018b; Schneider et al. 2018) and now extends these findings 
Table 5 Criterion correlations of corrective humor with the Four Dimensions of Humor Scale (4DHS) in each sample (21 samples in total)

\begin{tabular}{|c|c|c|c|c|c|c|c|c|}
\hline \multirow[t]{2}{*}{ Samples } & \multicolumn{2}{|c|}{$\begin{array}{l}\text { Social fun/ } \\
\text { entertaining }\end{array}$} & \multicolumn{2}{|c|}{ Mockery } & \multicolumn{2}{|c|}{ Humor ineptness } & \multicolumn{2}{|c|}{$\begin{array}{l}\text { Cognitive/ } \\
\text { reflective humor }\end{array}$} \\
\hline & $r$ & $95 \%$ CI & $r$ & $95 \% \mathrm{CI}$ & $r$ & $95 \% \mathrm{CI}$ & $r$ & $95 \% \mathrm{CI}$ \\
\hline Canada & .35 & {$[.24, .45]$} & .54 & {$[.45 .61]$} & .22 & {$[.08, .34]$} & .36 & {$[.24, .49]$} \\
\hline Czech Republic & .46 & {$[.34, .57]$} & .48 & {$[.39, .60]$} & .18 & {$[.01, .34]$} & .28 & {$[.17, .40]$} \\
\hline Chile (mainly Santiago) & .26 & {$[.17, .36]$} & .44 & {$[.36, .51]$} & .14 & {$[.04, .23]$} & .45 & {$[.37, .53]$} \\
\hline Croatia & .40 & {$[.29, .49]$} & .46 & {$[.34, .57]$} & .17 & {$[.04, .32]$} & .36 & {$[.26, .46]$} \\
\hline England & .37 & {$[.18, .53]$} & .50 & {$[.37, .62]$} & .11 & {$[-.09, .31]$} & .38 & {$[.16, .57]$} \\
\hline Estonia & .43 & {$[.32, .53]$} & .49 & {$[.39, .57]$} & .16 & {$[.05, .28]$} & .43 & {$[.30, .55]$} \\
\hline Germany & .43 & {$[.33, .52]$} & .50 & {$[.39, .61]$} & .14 & {$[.00, .30]$} & .51 & {$[.40, .61]$} \\
\hline Greece & .43 & {$[.36, .50]$} & .46 & {$[.39, .52]$} & .14 & {$[.07, .20]$} & .45 & {$[.37, .52]$} \\
\hline Italy (mainly North) & .32 & {$[.19, .44]$} & .40 & {$[.30, .49]$} & .06 & {$[-.08, .21]$} & .36 & {$[.23, .47]$} \\
\hline Malaysia (mainly Terengganu) & .38 & {$[.28, .49]$} & .59 & {$[.49, .69]$} & .34 & {$[.21, .46]$} & .46 & {$[.35, .56]$} \\
\hline Mexico (mainly Nuevo León) & .38 & {$[.24, .51]$} & .62 & {$[.50, .72]$} & .38 & {$[.24, .52]$} & .45 & {$[.30, .58]$} \\
\hline Poland & .45 & {$[.34, .54]$} & .50 & {$[.39, .59]$} & .14 & {$[.00, .26]$} & .36 & {$[.23, .49]$} \\
\hline Romania & .43 & {$[.32, .52]$} & .38 & {$[.27, .48]$} & .17 & {$[.04, .29]$} & .52 & {$[.41, .61]$} \\
\hline Russia (mainly St. Petersburg) & .37 & {$[.25, .48]$} & .51 & {$[.40, .61]$} & .13 & {$[.00, .25]$} & .26 & {$[.14, .39]$} \\
\hline Slovakia & .47 & {$[.39, .55]$} & .60 & {$[.52, .67]$} & .15 & {$[.04, .27]$} & .55 & {$[.46, .62]$} \\
\hline South Korea & .40 & {$[.29, .52]$} & .57 & {$[.49, .65]$} & .28 & {$[.16, .40]$} & .48 & {$[.38, .57]$} \\
\hline Switzerland (mainly Zurich) & .31 & {$[.17, .43]$} & .56 & {$[.45, .66]$} & .21 & {$[.08, .34]$} & .54 & {$[.42, .63]$} \\
\hline Taiwan & .46 & {$[.36, .54]$} & .59 & {$[.49, .67]$} & .41 & {$[.28, .51]$} & .38 & {$[.27, .47]$} \\
\hline Turkey (students) & .35 & {$[.25, .45]$} & .62 & {$[.54, .70]$} & .17 & {$[.05, .29]$} & .46 & {$[.38, .55]$} \\
\hline Turkey (workers/employees) & .36 & {$[.24, .47]$} & .52 & {$[.42, .61]$} & .07 & {$[-.07, .19]$} & .38 & {$[.26, .50]$} \\
\hline USA (mainly N.C.) & .49 & {$[.37, .61]$} & .63 & {$[.53, .72]$} & .30 & {$[.16, .44]$} & .40 & {$[.29, .52]$} \\
\hline Median across all samples & .40 & & .51 & & .17 & & .43 & \\
\hline
\end{tabular}

95\% CI = bootstrapped $95 \%$ confidence interval of the correlations $(r)$

Significant correlations highlighted in bold

to 25 European, American, Australasian, and Asian countries. Although the conceptualization and history of benevolent humor is strongly anchored in humanism and positive psychology, the observed relationships were mostly small and thus make only a small contribution to self-rated well-being. This has also been found for humor and comic styles in general (see Ruch and Heintz 2013, 2017; Ruch et al. 2018b), for example when controlling for the variance explained by broad personality traits.

While this seems a limitation, this small effect might be a more realistic representation of the humor-life satisfaction relationship than previous findings, but can also potentially accumulate when additional comic styles are included that are relevant for well-being (such as affiliative humor/fun, wit, irony, and cynicism, and laughing at oneself; Ford et al. 2016; McGhee 2010; Ruch et al. 2018b). Also, benevolent humor might be more relevant for specific populations (e.g., patients treated for severe depression, adolescents, or elderly people) rather than for healthy and young adults as represented in the present samples. Furthermore, given the effectiveness with which humor can be trained to enhance happiness and to reduce depressive symptoms (e.g., in humor-based positive psychology interventions; Wellenzohn et al. 2016, 2018), benevolent humor holds the potential for both 
continued research (e.g., experimental manipulations and longitudinal studies in the interplay of well-being and morality in humor; see also Ford et al. 2017) and applications (e.g., humor interventions at work and in clinical settings).

In terms of relationships with broad humor dimensions, benevolent humor correlated positively with social fun/entertaining humor and cognitive/reflective humor, and to a lower extent with mockery, as expected. Thus, benevolent humor was seen in every culture as a way to entertain others and at the same time as a way of being sophisticated, subtle, and intellectually challenging. While the positive correlation between benevolent humor and mockery (in all samples except for Italy, Russia [St. Petersburg], and Taiwan) might first seem counterintuitive due to their differences in intent (i.e., understanding vs. criticism), they both can share a cheerful humor production component as well as a playful component. The negative relationship of benevolent humor with humor ineptness, by contrast, was only supported in Estonia, Germany, Greece, and Russia (St. Petersburg), while a positive relationship emerged in Malaysia (mainly Terengganu) and most samples showed a non-significant relationship. This shows the importance of assessing different dimensions of humor and humorlessness separately, as they are not opposing ends on a bipolar spectrum. In other words, benevolent humor was both positively related to the three dimensions of humor, and unrelated to humor ineptness, a form of humorlessness.

Corrective humor was expected to be unrelated to life satisfaction, which was found both for the zero-order correlation and the partial correlation analyses, controlling for mockery. Although the median partial correlation was, as expected, slightly more positive than the zero-order correlation, both supported the interpretation that corrective humor does not play a role in life satisfaction in line with a previous study (Ruch et al. 2018b; cf. Mendiburo-Seguel and Heintz 2019). Rather than contributing to life satisfaction or subjective well-being, corrective humor might contribute to a healthy and well-functioning society; for instance, it might raise and enforce moral standards by increasing political participation (e.g., Hoffman and Young 2011), by providing resistance to power (Tang and Bhattacharya 2011) and by supporting public shaming (e.g., Hoffmann 2017; Phiddian 2017). Furthermore, corrective humor can provide people with a more socially accepted means to express their dissatisfaction, potentially empowering them and contributing to their eudaimonic, rather than subjective, well-being. These hypotheses need to be tested in future studies within the current positive-psychological and trait perspective, as most studies in the area stem from sociology, politics, or literature studies.

In terms of the broad humor dimensions, corrective humor had large positive correlations with fun, mockery, and cognitive/reflective humor, as expected. While the numerically largest correlation emerged with mockery, for Chile, Germany, and Romania the correlations with social fun/entertaining humor or cognitive/reflective humor were higher. Thus, slight differences in the extent to which corrective humor was associated with criticism (i.e., mockery) or with entertainment and sophistication were found between the samples in this investigation. Unexpectedly, small positive correlations also emerged with humor ineptness, again supporting the need to distinguish among different dimensions of humor and humorlessness; the largest correlations with humor ineptness emerged in Malaysia (Terengganu), Mexico, and Taiwan. Also, the correlation with mockery was especially strong in these three countries, indicating that corrective humor was more associated with criticism, humorlessness, and ineptness than with entertainment and sophistication.

These cross-cultural differences were in line with our expectations, as corrective humor or the expression of satire likely depends more on local censorship regulations and cultural conventions (Milner Davis 2016). It would be especially interesting to expand the cross-cultural nomological network of corrective humor to see which relationships are 
pancultural (as was found with life satisfaction) and which ones are culture-specific (as was found to some extent with the humor dimensions). It should however be noted that political and other forms of formal censorship vary from time to time according to the historic circumstances in which a culture finds itself. Also, these are perhaps not so much cultural but rather environmental factors, which may change over time (Milner Davis, personal communication, May 2019).

Interestingly, Japan had the lowest means in all scales (i.e., Bencor-R and SWLS), which is in line with previous cross-cultural comparisons of self-esteem (Schmitt and Allik 2005). The present study thus replicated that Japanese people tend to show more negative self-evaluations especially compared to people in Western countries. By contrast, the correlations between benevolent and corrective humor and life satisfaction were comparable between Japan and the other countries under investigation.

\section{Limitations and Directions for Future Studies}

The present study has several limitations. First, the 29 samples differed in their demographic composition (e.g., age, gender, and students vs. workers), which limits the comparability across the individual samples, but which makes it even more surprising that most samples yielded similar correlations for benevolent and corrective humor. However, parallelizing the sample composition would provide a more solid basis for conducting such cultural comparisons. Second, the samples did not represent all cultural groups adequately; for example, no African countries were included. Additionally, cultural subgroups within a country (e.g., Maoris in New Zealand, Native Americans in the USA) as well as different language groups (e.g., German-, French-, and Italian-speaking parts of Switzerland or English- and French-speaking parts of Canada) could be included as well. Extending the investigation to cultural value orientations (Schwartz 2015) to distinguish among different cultural regions would also allow determining how benevolent and corrective humor might be differently interpreted around the globe.

Third, only self-reports were employed. Extending the investigations to multimethod data (such as other-reports and actual humor behavior) would help to generalize the findings beyond self-perceptions. Although self-other convergence and relationships with behavior tests of humor appreciation and creation have been supported for benevolent and corrective humor in German-speaking countries and in Chile (Heintz 2019; MendiburoSeguel and Heintz 2019; Ruch et al. 2018a), future research should employ a cross-cultural multimethod approach. Fourth, only one aspect of well-being, life satisfaction (i.e., evaluative aspect of subjective well-being), was investigated. Extending future studies to multidimensional approaches, such as the mental health continuum (Keyes 2002), the PERMAmodel (Seligman 2011), or a comprehensive approach to thriving (Su et al. 2014), would provide a more comprehensive picture on how benevolent and corrective humor relate to well-being and thus provide a basis for humor interventions to foster well-being.

Fifth, the present study is purely correlational and thus does not allow the uncovering of the process and mechanisms underlying the relationships between humor and subjective well-being. Future studies should take qualitative and experimental approaches to determine whether benevolent humor and life satisfaction are shaped by similar sources across countries; for example, are both benevolent humor and life satisfaction more strongly influenced by satisfaction with oneself and with one's freedom in individualistic countries (such 
as the U.S.) rather than in more collectivistic countries, such as China (see Diener et al. 2003)? Additionally, given cross-cultural differences in the contents of humor (Alden et al. 1993; Davies 2012, 2017), it would be interesting to determine whether benevolent and corrective humor are directed at diverse targets and are distinctly expressed in different settings (due to cultural norms of openly sharing humor and criticism), which might in turn influence the assignment to higher-order humor dimensions as well as their relationships to other variables such as life satisfaction. Thus, this broad investigation provides the basis for more in-depth analyses of the interactions and causalities underlying humor and well-being within and across cultures.

Sixth, the 4DHS to assess four broad dimensions of humor is a preliminary measure, which needs further revisions to improve its reliability (esp. humor ineptness) and to support its validity. The relationships of benevolent and corrective humor and life satisfaction with the 4DHS scales should thus be interpreted with caution.

\section{Conclusions}

The present study investigated the relationships of benevolent and corrective humor with life satisfaction and broad humor dimensions in 29 samples from 25 countries. Specifically, benevolent humor was found to relate positively to life satisfaction (often also when controlling for social fun/entertaining humor), cognitive/reflective humor, social fun/entertaining humor, and to a lesser extent to mockery and (negatively) humor ineptness. Corrective humor was unrelated to life satisfaction (also when controlling for mockery), but positively related to all four broad humor dimensions, mostly to mockery, cognitive/reflective humor, and social fun/entertaining humor. Thus, benevolent and corrective humor showed a strong convergence of their nomological network across the 25 countries, making them viable constructs for future research and applications in well-being and positive psychology.

Acknowledgements We would like to thank Maria Araceli Alvarez-Gasca, Anna Andrzejewska, ChingHui Chen, Wojciech Chłopicki, Piotr Chruszczewski, Noreha Hashim, Elvira De Dios-Hernandez, Joanna Dybiec, Dariusz Kałuża, Sarah Kettmann, Maria Mocarz-Kleindienst, Theodoros Kyriazos, Hsiao-Hui Lin, Marhaini Mohd Noor, Andrew R. Olah, Ana Laura Parada-Lopez, Andrejs Andrievs Ramma, Dorota Rygiel, Grzegorz Szpila, Barbara Śpiewak, Patricia Vargas-Benitez, Alicja Witalisz, MA and PhD students at the Department of Theoretical and Applied Linguistics from Transilvania University of Brașov, and the Pirogov Russian National Research Medical University for their additional support in the translation and data collection. We would also like to thank Olenka Dworakowski for her help in analyzing and presenting the results. Finally, we would like to thank Jessica Milner Davis for her insightful comments on previous versions of the manuscript.

Funding Funding was provided by University of Rijeka (Grant No. uniri-drustv-18-27), Fondo Nacional de Desarrollo Científico y Tecnológico (Grant No. 11160661), Estonian Ministry of Education and Research (Grant No. IUT 22-5), European Union through the European Regional Development Fund (Grant No. TK 145 Centre of Excellence in Estonian Studies), Center for Social Sciences at Seoul National University (Center for Happiness Studies), The Featured Areas Research Center Program within the framework of the Higher Education Sprout Project by the Ministry of Education (MOE) in Taiwan (Institute for Research Excellence in Learning Sciences and the Chinese Language and Technology Center of National Taiwan Normal University (NTNU)).

\section{Compliance with Ethical Standards}

Conflict of interest The authors declare there is no conflict of interest. 


\section{References}

Alden, D. L., Hoyer, W. D., \& Lee, C. (1993). Identifying global and culture-specific dimensions of humor in advertising: A multinational analysis. Journal of Marketing. https://doi. org/10.1177/002224299305700205.

Chen, F. F. (2007). Sensitivity of goodness of fit indexes to lack of measurement invariance. Structural Equation Modeling: A Multidisciplinary Journal. https://doi.org/10.1080/10705510701301834.

Chen, G. H., \& Martin, R. A. (2007). A comparison of humor styles, coping humor, and mental health between Chinese and Canadian university students. Humor: International Journal of Humor Research. https://doi.org/10.1515/HUMOR.2007.011.

Cheung, G. W., \& Rensvold, R. B. (1999). Testing factorial invariance across groups: A reconceptualization and proposed new method. Journal of Management. https://doi.org/10.1177/014920639902500 101.

Craik, K. H., Lampert, M. D., \& Nelson, A. J. (1996). Sense of humor and styles of everyday humorous conduct. Humor: International Journal of Humor Research, 9, 273-302. https://doi.org/10.1515/ humr.1996.9.3-4.273.

Davies, C. (2012). Jokes and their relations to society. Berlin: Walter de Gruyter.

Davies, C. (2017). The mirth of nations. New York: Routledge.

Diener, E., Emmons, R. A., Larsen, R. J., \& Griffin, S. (1985). The satisfaction with life scale. Journal of Personality Assessment. https://doi.org/10.1207/s15327752jpa4901_13.

Diener, E., Oishi, S., \& Lucas, R. E. (2003). Personality, culture, and subjective well-being: Emotional and cognitive evaluations of life. Annual Review of Psychology. https://doi.org/10.1146/annurev.psych .54.101601.145056.

Diener, E., \& Suh, E. M. (Eds.). (2003). Culture and subjective well-being. Cambridge: MIT Press.

Eysenck, H. J. (1991). Dimensions of personality: 16, 5, or 3 ? Criteria for a taxonomic paradigm. Personality and Individual Differences. https://doi.org/10.1016/0191-8869(91)90144-Z.

Ford, T. E., Lappi, S. K., \& Holden, C. J. (2016). Personality, humor styles and happiness: Happy people have positive humor styles. Europe's Journal of Psychology. https://doi.org/10.5964/ejop.v12i3.1160.

Ford, T. E., Lappi, S. K., O’Connor, E. C., \& Banos, N. C. (2017). Manipulating humor styles: Engaging in self-enhancing humor reduces state anxiety. Humor: International Journal of Humor Research. https:// doi.org/10.1515/humor-2016-0113.

Freud, S. (1928). Humour. The International Journal of Psychoanalysis. Retrieved May 20, 2019 from https ://www.scribd.com/doc/34515345/Sigmund-Freud-Humor-1927.

Heintz, S. (2019). Locating eight comic styles in basic and broad concepts of humor: Findings from selfreports and behavior tests. Current Psychology. Advance online publication. https://doi.org/10.1007/ s12144-019-00179-z.

Heintz, S., \& Ruch, W. (2019). From four to nine styles: An update on individual differences in humor. Personality and Individual Differences. https://doi.org/10.1016/j.paid.2018.12.008.

Heintz, S., Ruch, W., Platt, T., Pang, D., Carretero-Dios, H., Dionigi, A., et al. (2018). Psychometric comparisons of benevolent and corrective humor across 22 countries: The virtue gap in humor goes international. Frontiers in Psychology. https://doi.org/10.3389/fpsyg.2018.00092.

Hoffmann, C. (2017). The anatomy of public shaming. In C. Hoffmann (Ed.), Stupid humanism (pp. 69-108). Cham: Palgrave Macmillan.

Hofmann, J., Heintz, S., Pang, D., \& Ruch, W. (2019). Differential relationships of light and darker forms of humor with mindfulness. Applied Research in Quality of Life. Advance online publication. https://doi. org/10.1007/s11482-018-9698-9.

Hoffman, L., \& Young, D. G. (2011). Satire, punch lines, and the nightly news: Untangling media effects on political participation. Communication Research Reports. https://doi.org/10.1080/08824 096.2011.565278.

Jorgensen, T. D., Pornprasertmanit, S., Schoemann, A. M., \& Rosseel, Y. (2018). semTools: Useful tools for structural equation modeling. R package version 0.5-1. Retrieved May 20, 2019 from https://CRAN.Rproject.org/package $=$ semTools.

Kazarian, S. S., \& Martin, R. A. (2006). Humor styles, culture-related personality, well-being, and family adjustment among Armenians in Lebanon. Humor: International Journal of Humor Research. https:// doi.org/10.1515/HUMOR.2006.020.

Keyes, C. L. (2002). The mental health continuum: From languishing to flourishing in life. Journal of Health and Social Behavior. https://doi.org/10.2307/3090197.

Kuiper, N. A., Grimshaw, M., Leite, C., \& Kirsh, G. (2004). Humor is not always the best medicine: Specific components of sense of humor and psychological well-being. Humor: International Journal of Humor Research, 17, 135-168. https://doi.org/10.1515/humr.2004.002. 
Kuppens, P., Realo, A., \& Diener, E. (2008). The role of positive and negative emotions in life satisfaction judgment across nations. Journal of Personality and Social Psychology. https://doi. org/10.1037/0022-3514.95.1.66.

Martin, R. A., \& Ford, T. (2018). The psychology of humor: An integrative approach. London: Academic Press.

Martin, R. A., \& Lefcourt, H. M. (1983). Sense of humor as a moderator of the relation between stressors and moods. Journal of Personality and Social Psychology, 45, 1313-1324. https://doi. org/10.1037/0022-3514.45.6.1313.

Martin, R. A., Kuiper, N. A., Olinger, L. J., \& Dance, K. A. (1993). Humor, coping with stress, self-concept, and psychological well-being. Humor: International Journal of Humor Research, 6, 89-104. https:// doi.org/10.1515/humr.1993.6.1.89.

Martin, R. A., Puhlik-Doris, P., Larsen, G., Gray, J., \& Weir, K. (2003). Individual differences in uses of humor and their relation to psychological well-being: Development of the Humor Styles Questionnaire. Journal of Research in Personality. https://doi.org/10.1016/S0092-6566(02)00534-2.

McGhee, P. E. (2010). Humor as survival training for a stressed-out world: The 7 Humor Habits Program. Bloomington: AuthorHouse.

McGrath, R. E. (2015). Character strengths in 75 nations: An update. The Journal of Positive Psychology, 10(1), 41-52. https://doi.org/10.1080/17439760.2014.888580.

Mendiburo-Seguel, A., \& Heintz, S. (2019). Comic styles and their relation to the sense of humor, humor appreciation, acceptability of prejudice, humorous self-image and happiness. Humor: International Journal of Humor Research. https://doi.org/10.1515/humor-2018-0151.

Milner Davis, J. (2016). Satire and its constraints: Case studies from Australia, Japan, and the People's Republic of China. Humor: International Journal of Humor Research. https://doi.org/10.1515/humor -2015-0080.

Milner Davis, J., \& Foyle, L. (2017). The Satirist, The Larrikin and the Politician. In J. Milner Davis (Ed.), Satire and politics: The interplay of heritage and practice (pp. 1-36). London: Palgrave.

Oishi, S., \& Diener, E. (2009). Goals, culture, and subjective well-being. In E. Diener (Ed.), Culture and well-being (pp. 93-108). Dordrecht: Springer.

Peterson, C., \& Seligman, M. E. P. (2004). Character strengths and virtues: A handbook and classification. New York: Oxford University Press.

Phiddian, R. (2017). Have they no shame? Observations on the effects of satire. In J. Milner Davis (Ed.), Satire and politics (pp. 251-263). London: Palgrave.

Proyer, R. T., Ruch, W., Ali, N. S., Al-Olimat, H. S., Amemiya, T., Adal, T. A., et al. (2009). Breaking ground in cross-cultural research on the fear of being laughed at (gelotophobia): A multi-national study involving 73 countries. Humor: International Journal of Humor Research. https://doi.org/10.1515/ HUMR.2009.012.

R Core Team (2019). R: A language and environment for statistical computing. Vienna, Austria: R Foundation for Statistical Computing. Retrieved May 20, 2019 from www.R-project.org.

Revelle, W. (2019). psych: Procedures for personality and psychological research. Evanston: Northwestern University. https://CRAN.R-project.org/package=psych.

Rosseel, Y. (2012). lavaan: An R package for structural equation modeling. Journal of Statistical Software. https://doi.org/10.18637/jss.v048.i02.

Ruch, W. (2012a). Towards a new structural model of the sense of humor: Preliminary findings. In Proceedings of the AAAI Fall symposium FS-12-02: artificial intelligence of humor (pp. 68-75). Menlo Park: AAAI Press.

Ruch, W. (2012b). Four Dimensions of Humor Scale. Unpublished manual, University of Zurich.

Ruch, W., \& Heintz, S. (2013). Humour styles, personality and psychological well-being: What's humour got to do with it? European Journal of Humour Research, 1, 1-24. https://doi.org/10.7592/EJHR2 013.1.4.ruch.

Ruch, W., \& Heintz, S. (2016). The virtue gap in humor: Exploring benevolent and corrective humor. Translational Issues in Psychological Science. https://doi.org/10.1037/tps0000063.

Ruch, W., \& Heintz, S. (2017). Experimentally manipulating items informs on the (limited) construct and criterion validity of the Humor Styles Questionnaire. Frontiers in Psychology, 8, 616. https://doi. org/10.3389/fpsyg.2017.00616.

Ruch, W., \& Heintz, S. (2019). On the dimensionality of humorous conduct and associations with humor traits and behaviors. Humor: International Journal of Humor Research. Advance online publication. https://doi.org/10.1515/humor-2018-0119.

Ruch, W., Heintz, S., Platt, T., Wagner, L., \& Proyer, R. T. (2018a). Broadening humor: Comic styles differentially tap into temperament, character, and ability. Frontiers in Psychology. https://doi.org/10.3389/ fpsyg.2018.00006. 
Ruch, W., Wagner, L., \& Heintz, S. (2018b). Humor, the PEN model of personality, and subjective wellbeing: Support for differential relationships with eight comic styles. RISU, 1, 31-44. Retrieved May 20, 2019 from www.risu.biz/wp-content/uploads/2018/01/Ruch_et_al.-RISU-11-2018-31-44-1.pdf.

Schermelleh-Engel, K., Moosbrugger, H., \& Müller, H. (2003). Evaluating the fit of structural equation models: Tests of significance and descriptive goodness-of-fit measures. Methods of Psychological Research Online, 8(2), 23-74.

Schmitt, D. P., \& Allik, J. (2005). Simultaneous administration of the Rosenberg Self-Esteem Scale in 53 nations: Exploring the universal and culture-specific features of global self-esteem. Journal of Personality and Social Psychology. https://doi.org/10.1037/0022-3514.89.4.623.

Schneider, M., Voracek, M., \& Tran, U. S. (2018). “A joke a day keeps the doctor away?" Meta-analytical evidence of differential associations of habitual humor styles with mental health. Scandinavian Journal of Psychology. https://doi.org/10.1111/sjop.12432.

Schwartz, S. H. (2015). Cultural values influence and constrain economic and social change. In L. Harrison \& Y. Yasin (Eds.), Culture matters in Russia-and everywhere (pp. 287-302). London: Lexington Books.

Seligman, M. E. P. (2011). Flourish: A visionary new understanding of happiness and well-being. New York: Free Press.

Su, R., Tay, L., \& Diener, E. (2014). The development and validation of the Comprehensive Inventory of Thriving (CIT) and the Brief Inventory of Thriving (BIT). Applied Psychology: Health and WellBeing. https://doi.org/10.1111/aphw.12027.

Tang, L., \& Bhattacharya, S. (2011). Power and resistance: A case study of satire on the Internet. Sociological Research Online. https://doi.org/10.5153/sro.2375.

Wellenzohn, S., Proyer, R. T., \& Ruch, W. (2016). Humor-based online positive psychology interventions: A randomized placebo-controlled long-term trial. The Journal of Positive Psychology. https://doi. org/10.1080/17439760.2015.1137624.

Wellenzohn, S., Proyer, R. T., \& Ruch, W. (2018). Who benefits from humor-based positive psychology interventions? The moderating effects of personality traits and sense of humor. Frontiers in Psychology. https://doi.org/10.3389/fpsyg.2018.00821.

Publisher's Note Springer Nature remains neutral with regard to jurisdictional claims in published maps and institutional affiliations.

\section{Affiliations}

Sonja Heintz ${ }^{1}$ (D) Willibald Ruch ${ }^{1} \cdot$ Simge Aykan ${ }^{2} \cdot$ Ingrid Brdar $^{3}$.

Dorota Brzozowska ${ }^{4} \cdot$ Hugo Carretero-Dios ${ }^{5} \cdot \mathrm{Hsueh}^{-C h i h} \mathrm{Chen}^{6,7,8,9}$. Władysław Chłopicki ${ }^{10} \cdot$ Incheol Choi $^{11,12}$ - Alberto Dionigi ${ }^{13} \cdot$ Róbert Ďurka $^{14}$. Thomas E. Ford ${ }^{15}$. Angelika Güsewell ${ }^{16}$. Robert B. Isler ${ }^{17}$. Alyona Ivanova ${ }^{18,19}$. Liisi Laineste $^{20}$. Petra Lajčiaková ${ }^{14}$. Chloe Lau ${ }^{21} \cdot$ Minha Lee $^{11}$. Stanca Măda ${ }^{22}$. Charles Martin-Krumm ${ }^{23,24}$. Andrés Mendiburo-Seguel ${ }^{25}$ - Ifu Migiwa ${ }^{26}$. Nailya Mustafi ${ }^{18} \cdot$ Atsushi Oshio $^{27} \cdot$ Tracey Platt $^{28} \cdot$ René T. Proyer $^{29}$. Angélica Quiroga-Garza ${ }^{30}$ - TamilSelvan Ramis ${ }^{31}$ - Răzvan Săftoiu 22 . Donald H. Saklofske ${ }^{21}$. Olga V. Shcherbakova ${ }^{32}$ - Alena Slezackova ${ }^{33}$. Anastasios Stalikas $^{34}$ • leva Stokenberga ${ }^{35}$. Jorge Torres-Marín ${ }^{5} \cdot$ Peter S. O. Wong ${ }^{36}$

Sonja Heintz

s.heintz@psychologie.uzh.ch

1 Section on Personality and Assessment, Department of Psychology, University of Zurich, Binzmühlestrasse 14/7, 8050 Zurich, Switzerland

2 Department of Physiology, Ankara University School of Medicine, Ankara, Turkey

3 Department of Psychology, Faculty of Humanities and Social Sciences, University of Rijeka, Rijeka, Croatia 
Institute of English, Faculty of Philology, University of Opole, Opole, Poland

5 Mind, Brain, and Behavior Research Center, Department of Research Methods in Behavioral Sciences, Faculty of Psychology, University of Granada, Granada, Spain

Department of Educational Psychology and Counseling, National Taiwan Normal University, Taipei, Taiwan

7 Institute for Research Excellence in Learning Sciences, National Taiwan Normal University, Taipei, Taiwan

Chinese Language and Technology Center, National Taiwan Normal University, Taipei, Taiwan

Haute Ecole de Musique Vaud Valais Fribourg, HES-SO, University of Applied Sciences and Arts Western Switzerland, Lausanne, Switzerland

Centre for Fundamental and Liberal Education, Universiti Malaysia Terengganu, Kuala Nerus, Terengganu, Malaysia 